\title{
A radiographic evaluation of elasticity in idiopathic scoliotic curves: are lateral bending films reliable enough to estimate curve elasticity?
}

\author{
Konstantinos Soultanis*, Nikolaos Pyrovolou, Georgios Karaliotas, \\ Iasonas Liveris, Vasilios Sakelariou, Georgios Mazis and Panayotis Soucacos
}

Address: 1st Department of Orthopaedics of the Medical School of Athens University, Athens, Greece

* Corresponding author

from $5^{\text {th }}$ International Conference on Conservative Management of Spinal Deformities

Athens, Greece. 3-5 April 2008

Published: 15 January 2009

Scoliosis 2009, 4(Suppl I):OI2 doi:10.1I86/I748-7I6I-4-SI-OI2

This abstract is available from: http://www.scoliosisjournal.com/content/4/SI/OI2

(c) 2009 Soultanis et al; licensee BioMed Central Ltd.

\section{Background}

Assessment of the elasticity of scoliotic curves is an important factor to plan further treatment in idiopathic scoliosis.

\section{Purpose}

To assess curve elasticity obtained from PA standing lateral bending radiographs in comparison to those taken when maximal manual supine traction is applied to the wrists and ankles in patients with idiopathic scoliosis.

\section{Patients and methods}

Evaluation of the elasticity of the scoliotic curve was done in 96 patients with idiopathic scoliosis with supine radiographs under manual traction and standing lateral bending radiographs.

\section{Results}

Measurements taken from lateral bending radiographs provided more reliable estimates of the postoperative correction compared to radiographs using manual wrist to ankle traction. Lateral bending was a more effective method to assess lumbar and thoracolumbar curves. The two tests were similar in ability to evaluate the elasticity of thoracic curves. A lack of patient cooperation in movement was attributed to inadequate assessment of curve elasticity seen in some of the lateral bending radiographs.

\section{Conclusion}

The lateral bending test usually is superior to manual traction method. Both methods for estimation of curve elasticity may be recommended because of the frequent, lack of patient cooperation in the lateral bending test. This compliance issue may result in an underestimation of the actual achieved correction.

\section{References}

I. Klepps SJ, Lenke LG, Bridwell KH, Bassett GS, Whorton J: Prospective comparison of flexibility radiographs in adolescent idiopathic scoliosis. Spine 200I, 26:E74-9.

2. Soucacos PK, Soucacos PN, Beris AE: Scoliosis elasticity assessed by manual traction: 49 juvenile and adolescent idiopathic cases. Acta Orthop Scand 1996, 67:169-72.

3. Vaughan JJ, Winter RB, Lonstein JE: Comparison of the use of supine bending and traction radiographs in the selection of the fusion area in adolescent idiopathic scoliosis. Spine 1996, 2I:2469-73

4. Watanabe K, Kawakami N, Nishiwaki Y, Goto M, Tsuji T, Obara T, Imagama S, Matsumoto M: Traction versus supine side-bending radiographs in determining flexibility: what factors influence these techniques? Spine 2007, 32:2604-9. 